\title{
THE INFLUENCE OF TYRE BALANCING IN NITROGEN FILLED TYRES USING STATISTICAL FEATURES AND RANDOM FOREST ALGORITHM
}

\section{P. S. ANOOP \& V. SUGUMARAN}

School of Mechanical Engineering, Vellore Institute of Technology, Chennai campus, Chennai, India

\begin{abstract}
Tyre condition monitoring systems (TCMS) are the safety systems used in a vehicle for measuring the condition of tyre like tyre pressure, temperature, balancing etc. Nowadays these systems play an important role in safety, because accidents were increasing very rapidly. The current technology TCMS uses direct sensors like pressure sensors or wheel speed sensors etc, which are highly expensive. This paper recommends a new indirect TCMS system using condition monitoring techniques and machine learning. For different balancing conditions vertical wheel hub vibrations are acquired from a moving nitrogen filled tyre using an accelerometer. The statistical features are extracted from the acquired signals and feature selected using j48 algorithm. Selected features are classified using random forest algorithm and reasonable high accuracy is obtained. The proposed model can be used for monitoring the tyre pressure and tyre balancing of an automobile successfully.

KEYWORDS: Tyre Condition Monitoring System, Machine Learning, Statistical Features, Random Forest, TPMS, Unbalance Effect
\end{abstract}

Received: Jun 09, 2020; Accepted: Jun 29, 2020; Published: Aug 05, 2020; Paper Id.: IJMPERDJUN2020636

\section{INTRODUCTION}

Tyres are circular parts that fit on the rims for enhancing the axial load of the automobile to the ground. Pneumatic and non-pneumatic tyres are the two basic types of it. Most of the tyres, used in passenger automobiles and bicycles are air filled structures. These tyres absorb vertical vibrations as it rolls and provide flexible cushion effect to the passenger. Non pneumatic tyres are airless that integrate wheel and tyre into a single component. These are used in special type of vehicles such as tractors, riding lawn movers etc. Considering the advantages, pneumatic tyres are worthier than nonpneumatic tyres as it ascertains noise reduced ride, durability and shock absorbing capability. Depending on the method of manufacture air-filled tyres are categorized as belted-ply, bias-ply and radial-ply.

Radial tyre is a type of tyre, where piles of fabric (nylon layer) arranged at right angle to the direction of travel. The major advantages of radial tyres are

- $\quad$ Its side walls are flexible.

- The contact area of radial tyres with road is high, so the vehicle stability will be higher.

- The rolling distance is low so fuel consumption will be less.

- Heat generation and vibration are less, so tyre life will be high.

The specification of the nitrogen filled tyre used for the experiment is coded as 165 / 80 R14 $85 \mathrm{~S}$. The various parameters in the tyre code are clearly explained in Figure 1 (A). The tyre selected for the current experiment is shown in Figure.2(B). 


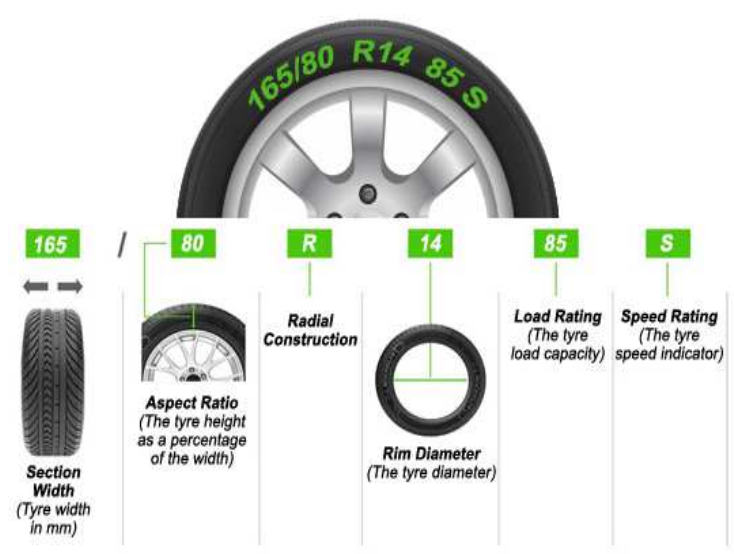

Figure 1: (A) Tyre Specification Diagram, (B) Tyre Selected For Current Experiment

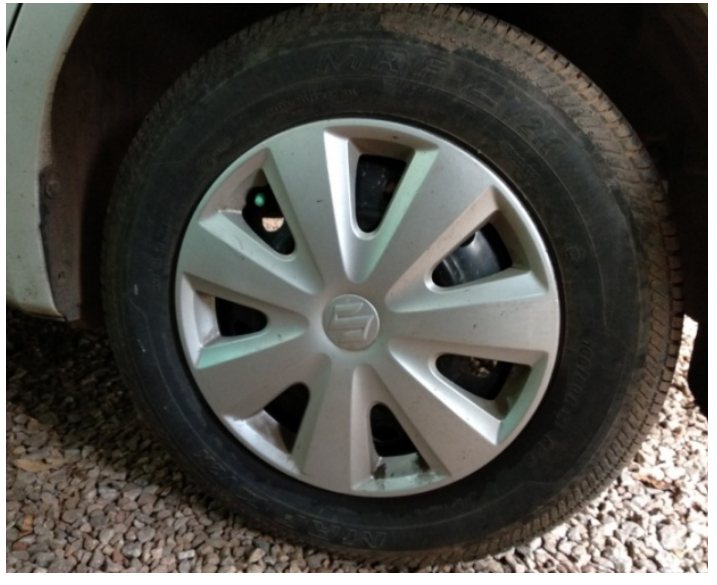

\subsection{Tyre Condition Monitoring System (TCMS)}

In this fast-growing automobile world, safety always has a prime preference. Here TCMS finds its place. TCMS alarms tyre - allied problems and thus ensure more secure mode of transportation. TCMS are small electronic subsystems that observe the tyre pressure and tyre balancing on individual wheels in an automobile. An automobile equipped with TCMS helps the driver to check the tyre condition whether it is having low pressure or something went badly amiss with the tyre. An effective TCMS can easily predict the malfunctioning of the tyre. Thus it decreases the possibility of tyre-related road accidents. According to the method of data acquisition, TCMS can be classified into-Direct TCMS (DTCMS) and Indirect TCMS (ITCMS). A direct TCMS as the name suggests measures the pressure and tyre condition from the pressure sensor and then transforms the data into the controlling unit fitted at the dashboard. Whereas in Indirect TCMS, the pressure and tyre condition are measured indirectly from the wheel speed sensors and then transforms the data into the controlling unit. The advantages of ITCMS are- affordable cost, easy maintenance and reliability. This study depends on indirect TCMS so as to prove that ITCMS have more advantages than that of DTCMS.

In recent years, research opportunities of ITCMS in current trending technologies such as machine learning, artificial intelligence, etc. are having wide acceptance[1]. Initially ITCMS are functioning according to the principle that low pressure tyres have reduced diameter when compared to the properly inflated tyres. The main drawback of this system is that it fails to detect if all the four tyres are simultaneously under inflated. But later studies rectified this drawback by means of spectrum analysis and advanced signal processing techniques [2]. Rolling resistance of a tyre is the energy needed to maintain the tyre movement. Schuring and Futamura stated that as the rolling resistance coefficient decreases, the fuel efficiency increases because of the stiffness of the tyre.[3]. Robinson et al prepared an experimental setup in which accelerometer was fitted with the tyre and the vibrations were created artificially by hitting the tyre with a hammer[4].

In another study Craighead put forward a technique, in which he made use of vibration measurements and frequency spectrum analysis of the tyre under normal conditions to find the tyre pressure and wheel balance. The accuracy obtained was relatively less than $12 \%$ and the measure of unbalance was determined[5]. Hasan et al proposed a technique that utilized air pressure in pneumatic tyres. If the tyre pressure varied, then a cautious warning would register. The user could revise the minimum and maximum tyre pressure level[6].

Tyre life span is closely related with tyre pressure. A minute deflection in tyre pressure (17\%) may decrease the tyre's life span by $25 \%$ and increase the total consumption of fuel by $2 \%$ [7]. Wu et al. proposed different energy 
harvesting methods using TPMS and have concluded the importance of piezoelectric sensors in TPMS[8]. Some of the systems exclusively in commercial vehicle which determine tyre pressure and tyre radius using Vehicle Stability Sensor and GPS[9]. Garcia-pozuelo et al. (2017) developed a strain-based technique to monitor the rolling speed, vertical load, inflation pressure by adding fuzzy logic[10].

The studies based on indirect tyre pressure monitoring system need to gain momentum. Svensson et al. proposed an ITPMS with the help of supervised machine learning. In the study the system permits to detect thread depth and incorrect tyre pressure. And the result shows that the proposed system has an accuracy of 90.54\%[11]. In general, several significant experiments were put in to effect in the field of both DTCMS and ITCMS. But just a few number of studies were carried out in detecting both tyre pressure and tyre balancing simultaneously using ITCMS. Moreover proper emphasis on experiments based on machine learning was also very meagre. But these are the needs of the hour. In this context, this study proposes a novel approach through which it claims that both tyre pressure and tyre balancing can be measured using indirect TCMS with the help of machine learning techniques. The detailed methodology of the proposed system as shown in Figure. 2.

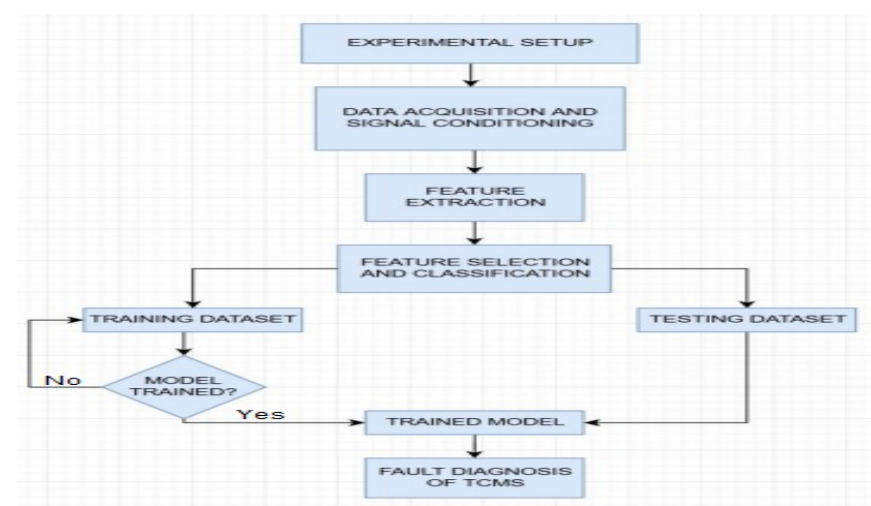

Figure 2: Methodology of Proposed ITCMS.

\section{EXPERIMENTAL SETUP}

Mainly an accelerometer is used for acquiring vibration signals. In this experiment, a tri-axial accelerometer was fitted with the back left wheel hub of the selected vehicle in order to avoid the unwanted engine vibration signals (Refer Figure4). 'NI USB-6001' was used as data acquisition (DAQ) device. In order to avoid the external electronic noise, a shielded wire was connected in between accelerometer and DAQ. The specifications of the MEMS accelerometer and NI USB-6001 were given in Table 1 and Table 2 respectively.

As shown in Table 3, the conditions -40 balance, -20 balances, 0 balances, +20 balances and +40 balances where chosen for data collection of High, Normal, Puncture and Idle cases (refer Table 3). The range of test driving speed was between $10 \mathrm{~km} / \mathrm{hr}$ and $100 \mathrm{~km} / \mathrm{hr} .19 \mathrm{psi}, 31 \mathrm{psi}$ and 40psi were taken as the tyre pressure of puncture, normal and high conditions respectively. Riding a speed below $10 \mathrm{~km} / \mathrm{hr}$, without sufficient amplitude and vibration, was taken as Idle. A balanced study was conducted by collecting 60 samples in all cases mainly High, Normal, Puncture and idle. On the whole, a total of 1200 samples were obtained. Each of these signals was having 5000 data points and $1 \mathrm{kHz}$ sample rate. 


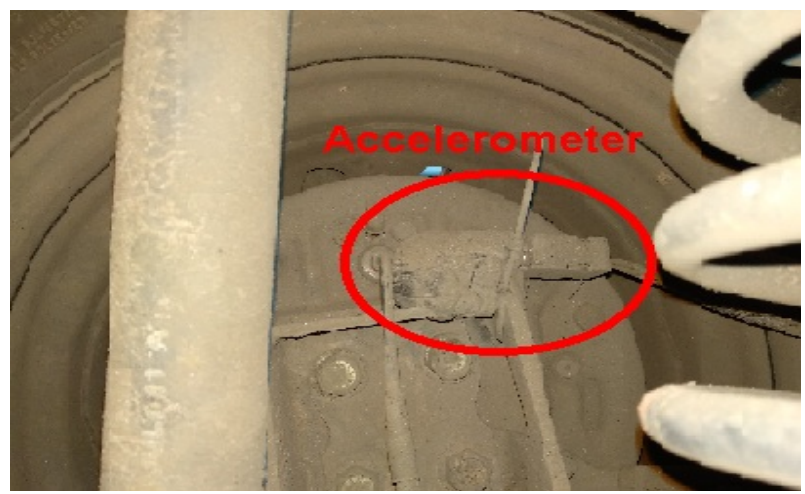

Figure 3: MEMS Accelerometer Fitted on the Axel of the Rear Left Wheel.

Table 1: MEMS Accelerometer Specification

\begin{tabular}{ll}
\hline FEATURES & SPECIFICATION \\
\hline Make & Freescale Semiconductor \\
Weight & $<1 \mathrm{~g}$ (accelerometer only) \\
& $5 \mathrm{~g}$ with supporting electronics \\
Type & MEMS \\
Number of Axis & 3 \\
Description & $\pm 1.5 \mathrm{~g}$ \\
& $\pm 6 \mathrm{~g}$ \\
Frequency & Selectable range \\
& $1-400 \mathrm{~Hz}(\mathrm{X}$ and $\mathrm{Y}$ axis) \\
Resonance Frequency & $1-300 \mathrm{~Hz}(\mathrm{Z}$ axis) \\
& $6 \mathrm{kHz} \mathrm{X}$ and $\mathrm{Y}$ axis) \\
Sensitivity & $3.4 \mathrm{kHz}(\mathrm{Z}$ axis) \\
& $800 \mathrm{mV} / \mathrm{g} @ 1.5 \mathrm{~g}$ \\
Connector & $206 \mathrm{mV} / \mathrm{g} @ 6 \mathrm{~g}$ \\
& $\mathrm{LGA}-14$ Package \\
& (SMD component) \\
\hline
\end{tabular}

Table 2: Specification of Data Acquisition System Used for MEMS Sensor

\begin{tabular}{ll}
\hline FEATURES & SPECIFICATION \\
\hline Make & National Instruments(NI) \\
PC communication & USB \\
Number of input Channel & \\
$\quad$ Differential & 4 \\
$\quad$ Single-ended & 8 \\
ADC Type & Successive approximation \\
ADC resolution & $14-\mathrm{bit}$ \\
Max sampling rate (aggregate) & $20 \mathrm{kS} / \mathrm{s}$ \\
Max sampling rate (aggregate) & $20 \mathrm{kS} / \mathrm{s}$ \\
\hline
\end{tabular}

Table 3: Balanced and Unbalanced Mass Levels

\begin{tabular}{|r|c|c|}
\hline Conditions & Weight Added(g) & Wheel Position \\
\hline-40 Balance & $0 \mathrm{~g}$ & Rear Left \\
\hline-20 Balance & $20 \mathrm{~g}$ & Rear Left \\
\hline 0 Balance & $40 \mathrm{~g}$ & Rear Left \\
\hline+20 Balance & $60 \mathrm{~g}$ & Rear Left \\
\hline+40 Balance & $80 \mathrm{~g}$ & Rear Left \\
\hline
\end{tabular}




\subsection{Sampling Rate Calculation}

The tyre used for this particular study was $165 / 80$ radial. The tyre radius(R) was rated as $30.1 \mathrm{~cm}$. The maximum and minimum speed of the study was $100 \mathrm{~km} / \mathrm{hr}$ and $10 \mathrm{~km} / \mathrm{hr}$ respectively. Based on the study[12], the minimum and maximum frequency is $1.47 \mathrm{~Hz}$ and $14.73 \mathrm{~Hz}$ respectively. Considering Nyquist Shannon sampling theorem, the minimum sampling rate will have to be greater than or equal to $29.46 \mathrm{~Hz}$ [13]. So this study prefers to take $1 \mathrm{kHz}$ as sampling rate.

\section{FEATURE EXTRACTIONS}

Machine learning consists of 3 steps-feature extraction, feature selection and feature classification. Feature extraction is a feature reduction process in which it aligns the available features according to their importance in classification. Targeted vibration signals for the conditions -40 balance, -20 balance, 0 balance, +20 balance and +40 balance were chosen for data collection of High, Normal, Puncture and Idle cases. This study used statistical feature extraction, which is one of the best and common feature extraction techniques. Statistical features extracted were mean, median, mode, kurtosis, skewness, sample variance, standard error, standard deviation, sum, minimum, maximum and range.

\section{FEATURE SELECTIONS}

The features extracted during feature extraction technique were tested using j48decision tree algorithm. The involvement of each feature tested and the features influencing less for the classification were filtered for decreasing computational load of the system. In[14] the detailed procedure of feature selection using j48 decision tree algorithm was clearly explained. Table 4 describes the features selected for different conditions. Figure 4 shows the decision tree generated from j48 decision tree algorithm.

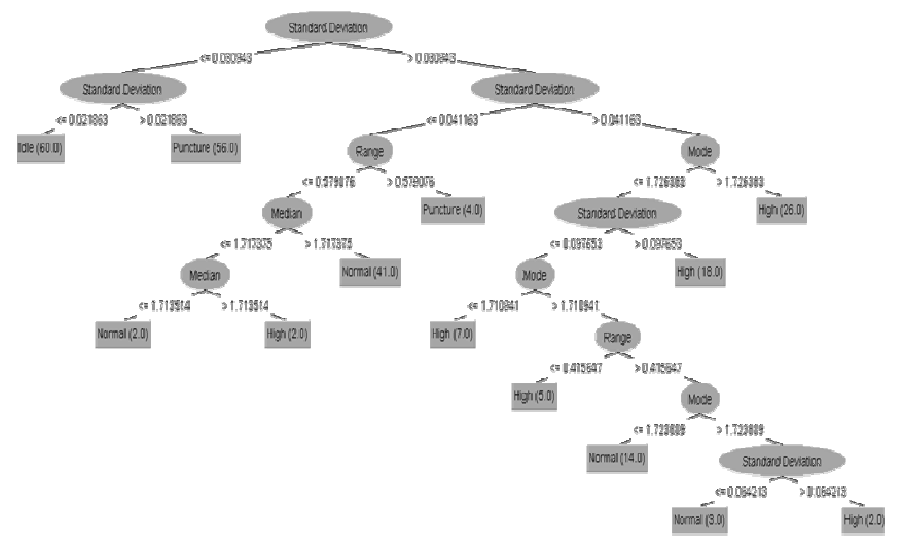

Figure 4: Decision Tree Generated From J48 Decision Tree Algorithm.

Table 4: The Features Selected for Different Conditions

\begin{tabular}{|c|c|}
\hline Balance Condition & Features Selected \\
\hline-40 Balance & Mean, Standard Error, Mode, Skewness, Range \\
\hline-20 Balance & Mean, Standard Error, Standard Deviation, Skewness \\
\hline 0 Balance & Median, Mode, Standard Deviation, Range \\
\hline+20 Balance & Mean, Standard Error, Mode, Sample Variance, Kurtosis, Skewness, Minimum \\
\hline+40 Balance & Standard Error, Median, Sample Variance, Kurtosis, Skewness, Range, \\
Minimum
\end{tabular}




\section{FEATURE CLASSIFICATION-RANDOM FOREST (RF) ALGORITHM}

Random Forest algorithm is a commonly accepted classifier due to the accuracy level obtained among different data mining techniques. [15]. Random forest algorithm is a collection of trees, which are developed by a binary partition technique. These trees are formed with the following conditions.

- Number of training sets be 'N' and attributes in the classifier be 'M'.

- Let ' $\mathrm{m}$ ' be the input variable which is used to find the decision at the node, with $\mathrm{m}<\mathrm{M}$

- Training case ' $\mathrm{N}$ ' is replaced by ' $\mathrm{n}$ ' times and also choose ' $\mathrm{m}$ ' variable random out of the ' $\mathrm{M}$ ' at each node of the tree. Best split is used at the nodes.

- The value ' $m$ ' should be maintained constantly while growing the forest.

- $\quad$ Each tree is grown to maximum extent.

- The error rate of the forest depends on the correlation of the two trees and strength of the individual tree. Generalization error is given by the formula,

Generalization error $\leq \frac{\bar{\rho}\left(1-s^{2}\right)}{s^{2}}$

Where, $\rho$ is an average correlation among the trees. $s$ is a measure of strength of tree classifier[16].

\section{RESULTS AND DISCUSSIONS}

\subsection{Zero Balanced Condition Using Random Forest Classifier}

The tyre selected for this study was set to balanced condition, which means that there was no additional weight rather than the balancing weight fitted with the tyre. The total balancing weight fitted was $40 \mathrm{~g}$ and the tyre was inflated with nitrogen. The signals were acquired for different pressure conditions such as High, Normal, Puncture and Idle. The experiments were conducted with in the speed limit of $10 \mathrm{~km} / \mathrm{hr}$ and $100 \mathrm{~km} / \mathrm{hr}$. Statistical features were extracted from the different class of signals. The feature selection was done using $\mathrm{j} 48$ algorithm and features were classified using random forest classifier.

From Figure 5, it is evident that Random forest classifier provides the maximum classification accuracy of 95.41 $\%$ for zero balanced nitrogen condition. The confusion matrix for zero balanced nitrogen condition generated by trained random forest classifier is shown in Table 5. Table 6 shows class-wise detailed accuracy for the trained random committee classifier for balanced air condition.

From Table.5, the correctly classified instances (out of 60) were represented as diagonal elements in the confusion matrix. From the matrix, one can notice that 59/60 of 'idle' instances were correctly classified followed by 'puncture' instances where 59/60 are correctly classified. 56/60 instances are correctly classified for 'high' state and 55/60 instances for 'normal' state[17].

Table 6 shows for the random forest classifier under zero balanced condition, kappa statistics was measured to be 0.9389. It measured the arrangement of likelihood with the true class. The mean absolute error was used to measure the closeness of the prediction to the ultimate result which was measured to be 0.047 . The root mean square error value was measured to be $0.1519[18]$. 
Table 5: Confusion Matrix Generated for Zero Balanced Nitrogen Condition

\begin{tabular}{|c|c|c|c|c|}
\hline Classified as & 0HigN2 & 0NorN2 & 0PunN2 & 0IdlN2 \\
\hline 0HigN2 & 56 & 4 & 0 & 0 \\
\hline 0NorN2 & 5 & 55 & 0 & 0 \\
\hline 0PunN2 & 0 & 1 & 59 & 0 \\
\hline 0IdlN2 & 0 & 0 & 1 & 59 \\
\hline
\end{tabular}

Table 6: Detailed Accuracy by Class for Zero Balanced Nitrogen Condition

\begin{tabular}{|c|c|c|c|c|c|c|c|c|}
\hline $\begin{array}{c}\text { TP } \\
\text { Rate }\end{array}$ & $\begin{array}{c}\text { FP } \\
\text { Rate }\end{array}$ & Precision & Recall & $\begin{array}{c}\text { F- } \\
\text { Measure }\end{array}$ & MCC & $\begin{array}{c}\text { ROC } \\
\text { Area }\end{array}$ & $\begin{array}{c}\text { PRC } \\
\text { Area }\end{array}$ & Class \\
\hline 0.933 & 0.028 & 0.918 & 0.933 & 0.926 & 0.901 & 0.990 & 0.974 & 0HigN2 \\
\hline 0.917 & 0.028 & 0.917 & 0.917 & 0.917 & 0.889 & 0.986 & 0.952 & 0NorN2 \\
\hline 0.983 & 0.006 & 0.983 & 0.983 & 0.983 & 0.978 & 0.997 & 0.981 & 0PunN2 \\
\hline 0.983 & 0.000 & 1.000 & 0.983 & 0.992 & 0.989 & 0.992 & 0.987 & 0IdIN2 \\
\hline 0.954 & 0.015 & 0.955 & 0.954 & 0.954 & 0.939 & 0.991 & 0.974 & $\begin{array}{c}\text { Weighted } \\
\text { Avg, }\end{array}$ \\
\hline
\end{tabular}

\subsection{Balanced Condition Using Random Forest Classifier}

In this condition the total balancing weight added to the selected tyre was $20 \mathrm{~g}$ instead of $40 \mathrm{~g}$ (Refer section 6.1). The confusion matrix for -20 balanced nitrogen condition generated by trained random forest classifier is shown in Table 7 . Table 8 shows class-wise detailed accuracy for the trained random forest classifier for -20 balanced nitrogen conditions.

Table 8 shows for the random forest classifier under -20 balanced condition; kappa statistics was measured to be 0.9111. It measured the arrangement of likelihood with the true class. The mean absolute error was used to measure the closeness of the prediction to the ultimate result which was measured to be 0.054 . The root mean square error value was measured to be 0.1649 .

Table 7: Confusion Matrixes Generated for -20 Balanced Nitrogen Condition

\begin{tabular}{|c|c|c|c|c|}
\hline Classified as & $\mathbf{- 2 0 H i g N 2}$ & $\mathbf{- 2 0 N o r N 2}$ & $\mathbf{- 2 0 P u n N 2}$ & $\mathbf{- 2 0 I d I N 2}$ \\
\hline $\mathbf{- 2 0 H i g N 2}$ & 55 & 4 & 1 & 0 \\
\hline $\mathbf{- 2 0 N o r N 2}$ & 6 & 51 & 3 & 0 \\
\hline$-\mathbf{2 0}$ PunN2 & 1 & 1 & 58 & 0 \\
\hline -20IdlN2 & 0 & 0 & 0 & 60 \\
\hline
\end{tabular}

Table 8: Detailed Accuracy by Class for -20 Balanced Nitrogen Condition

\begin{tabular}{|c|c|c|c|c|c|c|c|c|}
\hline $\begin{array}{c}\text { TP } \\
\text { Rate }\end{array}$ & $\begin{array}{c}\text { FP } \\
\text { Rate }\end{array}$ & Precision & Recall & $\begin{array}{c}\text { F- } \\
\text { Measure }\end{array}$ & MCC & $\begin{array}{c}\text { ROC } \\
\text { Area }\end{array}$ & $\begin{array}{c}\text { PRC } \\
\text { Area }\end{array}$ & Class \\
\hline 0.917 & 0.039 & 0.887 & 0.917 & 0.902 & 0.868 & 0.986 & 0.969 & -20HigN2 \\
\hline 0.850 & 0.028 & 0.911 & 0.850 & 0.879 & 0.842 & 0.969 & 0.877 & -20NorN2 \\
\hline 0.967 & 0.022 & 0.935 & 0.967 & 0.951 & 0.934 & 0.989 & 0.981 & -20PunN2 \\
\hline 1.000 & 0.000 & 1.000 & 1.000 & 0.933 & 0.911 & 0.986 & 0.957 & -20IdIN2 \\
\hline 0.933 & 0.022 & 0.933 & 0.933 & 0.933 & 0.911 & 0.986 & 0.957 & $\begin{array}{c}\text { Weighted } \\
\text { Avg, }\end{array}$ \\
\hline
\end{tabular}




\section{3. -40 Balanced Condition Using Random Forest Classifier}

In this condition the total balancing weight added to the selected tyre was $0 \mathrm{~g}$ instead of $40 \mathrm{~g}$ (Refer section 6.1). The confusion matrix for -40 balanced nitrogen condition generated by trained random forest classifier is shown in Table 9 . Table 10 shows class-wise detailed accuracy for the trained random forest classifier for -40 balanced nitrogen condition.

Table 10 shows for the random forest classifier under -40 balanced conditions; kappa statistics was measured to be 0.8944. It measured the arrangement of likelihood with the true class. The mean absolute error was used to measure the closeness of the prediction to the ultimate result which was measured to be 0.0739 . The root mean square error value was measured to be 0.1831 .

Table 9: Confusion Matrix Generated for -40 Balanced Nitrogen Condition

\begin{tabular}{|c|c|c|c|c|}
\hline Classified as & $-\mathbf{4 0 H i g N 2}$ & $\mathbf{- 4 0 N o r N 2}$ & $\mathbf{- 4 0 P u n N 2}$ & $\mathbf{- 4 0 I d I N 2}$ \\
\hline $\mathbf{- 4 0 H i g N 2}$ & 53 & 5 & 2 & 0 \\
\hline$-\mathbf{4 0 N o r N 2}$ & 0 & 55 & 3 & 0 \\
\hline$-\mathbf{4 0 P u n N 2}$ & 1 & 4 & 54 & 1 \\
\hline-40 IdIN2 & 0 & 0 & 1 & 59 \\
\hline
\end{tabular}

Table 10: Detailed Accuracy by Class for -40 Balanced Nitrogen Condition

\begin{tabular}{|c|c|c|c|c|c|c|c|c|}
\hline $\begin{array}{c}\text { TP } \\
\text { Rate }\end{array}$ & $\begin{array}{c}\text { FP } \\
\text { Rate }\end{array}$ & Precision & Recall & $\begin{array}{c}\text { F- } \\
\text { Measure }\end{array}$ & MCC & $\begin{array}{c}\text { ROC } \\
\text { Area }\end{array}$ & $\begin{array}{c}\text { PRC } \\
\text { Area }\end{array}$ & Class \\
\hline 0.883 & 0.017 & 0.946 & 0.883 & 0.914 & 0.887 & 0.985 & 0.961 & -40HigN2 \\
\hline 0.917 & 0.050 & 0.859 & 0.917 & 0.887 & 0.849 & 0.973 & 0.939 & - -40NorN2 \\
\hline 0.900 & 0.033 & 0.900 & 0.900 & 0.900 & 0.867 & 0.990 & 0.963 & $-\mathbf{- 4 0 P u n 2 2}$ \\
\hline 0.983 & 0.006 & 0.983 & 0.983 & 0.983 & 0.978 & 1.000 & 1.000 & $-\mathbf{- 4 0 I d I 2 2}$ \\
\hline 0.921 & 0.026 & 0.922 & 0.921 & 0.921 & 0.895 & 0.987 & 0.966 & $\begin{array}{c}\text { Weighted } \\
\text { Avg, }\end{array}$ \\
\hline
\end{tabular}

\section{4. +20 Balanced Condition Using Random Forest Classifier}

In this condition the total balancing weight added to the selected tyre was $60 \mathrm{~g}$ instead of $40 \mathrm{~g}$ (Refer section 6.1). The confusion matrix for +20 balanced nitrogen condition generated by trained random forest classifier is shown in Table 11 . Table 12 shows class-wise detailed accuracy for the trained random forest classifier for +20 balanced nitrogencondition.

Table 12 shows for the random forest classifier under +20 balanced conditions; kappa statistics was measured to be 0.9333 . It measures the arrangement of likelihood with the true class. The mean absolute error is used to measure the closeness of the prediction to the ultimate result which was measured to be 0.0609 . The root mean square error value was measured to be 0.1566 .

Table 11: Confusion Matrix Generated for +20 Balanced Nitrogen Condition

\begin{tabular}{|c|c|c|c|c|}
\hline Classified as & +20HigN2 & +20NorN2 & +20PunN2 & +20IdlN2 \\
\hline +20HigN2 & 59 & 1 & 0 & 0 \\
\hline +20NorN2 & 2 & 55 & 3 & 0 \\
\hline +20PunN2 & 1 & 5 & 54 & 0 \\
\hline +20IdIN2 & 0 & 0 & 0 & 60 \\
\hline
\end{tabular}


Table 12: Detailed Accuracy by Class for +20 Balanced Nitrogen Condition

\begin{tabular}{|c|c|c|c|c|c|c|c|c|}
\hline $\begin{array}{c}\text { TP } \\
\text { Rate }\end{array}$ & $\begin{array}{c}\text { FP } \\
\text { Rate }\end{array}$ & Precision & Recall & $\begin{array}{c}\text { F- } \\
\text { Measure }\end{array}$ & $\mathrm{MCC}$ & $\begin{array}{l}\text { ROC } \\
\text { Area }\end{array}$ & $\begin{array}{l}\text { PRC } \\
\text { Area }\end{array}$ & Class \\
\hline 0.983 & 0.017 & 0.952 & 0.983 & 0.967 & 0.956 & 0.994 & 0.980 & +20 HigN2 \\
\hline 0.917 & 0.033 & 0.902 & 0.917 & 0.909 & 0.879 & 0.981 & 0.942 & +20 NorN2 \\
\hline 0.900 & 0.017 & 0.947 & 0.900 & 0.923 & 0.899 & 0.993 & 0.982 & +20 PunN2 \\
\hline 1.000 & 0.000 & 1.000 & 1.000 & 1.000 & 1.000 & 1.000 & 1.000 & +20 IdlN2 \\
\hline 0.950 & 0.017 & 0.950 & 0.950 & 0.950 & 0.933 & 0.992 & 0.976 & $\begin{array}{c}\text { Weighted } \\
\text { Avg, }\end{array}$ \\
\hline
\end{tabular}

\section{5. +40 Balanced Condition Using Random Forest Classifier}

In this condition the total balancing weight added to the selected tyre was $80 \mathrm{~g}$ instead of $40 \mathrm{~g}$ (Refer section 6.1). The confusion matrix for +40 balanced nitrogen condition generated by trained random forest classifier is shown in Table 13. Table 14 shows class-wise detailed accuracy for the trained random forest classifier for +40 balanced nitrogencondition.

Table 14 shows for the random forest classifier under +40 balanced conditions; kappa statistics was measured to be 0.8722 . It measured the arrangement of likelihood with the true class. The mean absolute error was used to measure the closeness of the prediction to the ultimate result which was measured to be 0.1059 . The root mean square error value was measured to be 0.2167 .

Table 13: Confusion Matrix Generated for +40 Balanced Nitrogen Condition

\begin{tabular}{|c|c|c|c|c|}
\hline Classified as & +40HigN2 & +40NorN2 & +40PunN2 & +40IdlN2 \\
\hline +40HigN2 & 53 & 7 & 0 & 0 \\
\hline +40NorN2 & 3 & 53 & 4 & 0 \\
\hline +40PunN2 & 1 & 8 & 51 & 0 \\
\hline +40IdIN2 & 0 & 0 & 0 & 60 \\
\hline
\end{tabular}

Table 14: Detailed Accuracy by Class for +40 Balanced Nitrogen Condition

\begin{tabular}{|c|c|c|c|c|c|c|c|c|}
\hline $\begin{array}{c}\text { TP } \\
\text { Rate }\end{array}$ & $\begin{array}{c}\text { FP } \\
\text { Rate }\end{array}$ & Precision & Recall & $\begin{array}{c}\text { F- } \\
\text { Measure }\end{array}$ & MCC & $\begin{array}{l}\text { ROC } \\
\text { Area }\end{array}$ & $\begin{array}{l}\text { PRC } \\
\text { Area }\end{array}$ & Class \\
\hline 0.883 & 0.022 & 0.930 & 0.883 & 0.906 & 0.876 & 0.973 & 0.914 & +40 HigN2 \\
\hline 0.883 & 0.083 & 0.779 & 0.883 & 0.828 & 0.769 & 0.936 & 0.766 & +40 NorN2 \\
\hline 0.850 & 0.022 & 0.927 & 0.850 & 0.887 & 0.853 & 0.971 & 0.940 & +40 PunN2 \\
\hline 1.000 & 0.000 & 1.000 & 1.000 & 1.000 & 1.000 & 1.000 & 1.000 & +40IdlN2 \\
\hline 0.904 & 0.032 & 0.909 & 0.904 & 0.905 & 0.874 & 0.970 & 0.905 & $\begin{array}{l}\text { Weighted } \\
\text { Avg, }\end{array}$ \\
\hline
\end{tabular}

\subsection{Effect Of Balanced and Unbalanced Conditions Using Random Forest Classifier}

The main parameters which depend on random forest classifier are random number seed and number of trees. The variation of these parameters with respect to classification accuracy (\%) is as shown in Figure 5 and Figure 6.

In Figure 5 and Figure 6, it is clearly showed that the zero unbalance and +20 unbalance were having almost same accuracy levels. Other balancing conditions like -20 balance having an accuracy level lower than that of these two levels. - 
40 balance and +40 balance conditions having accuracy level lower than that of the rest of all other conditions.

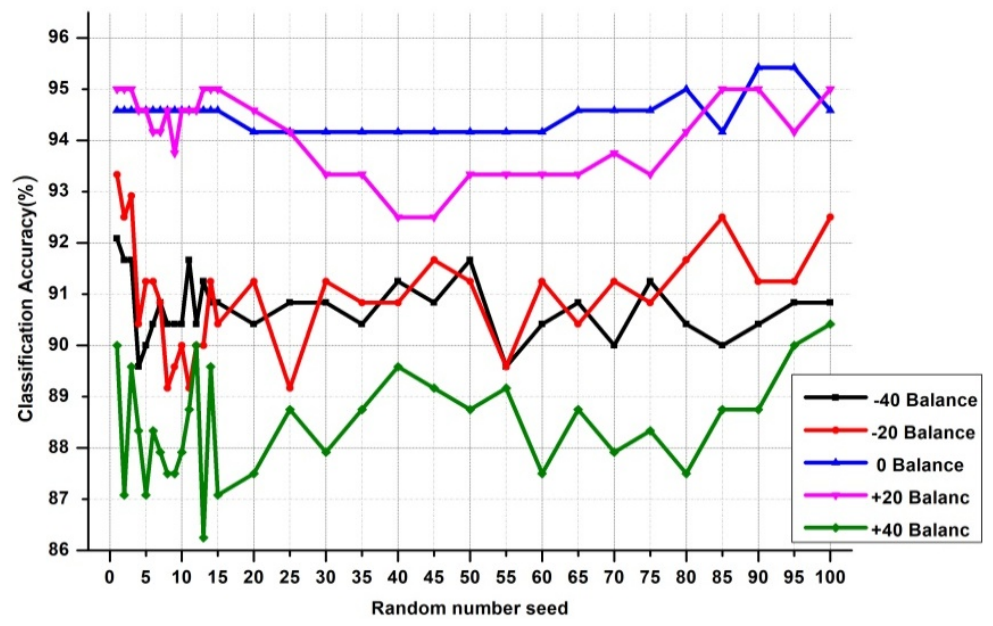

Figure 5: Random Seed Varies with Classification Accuracy.

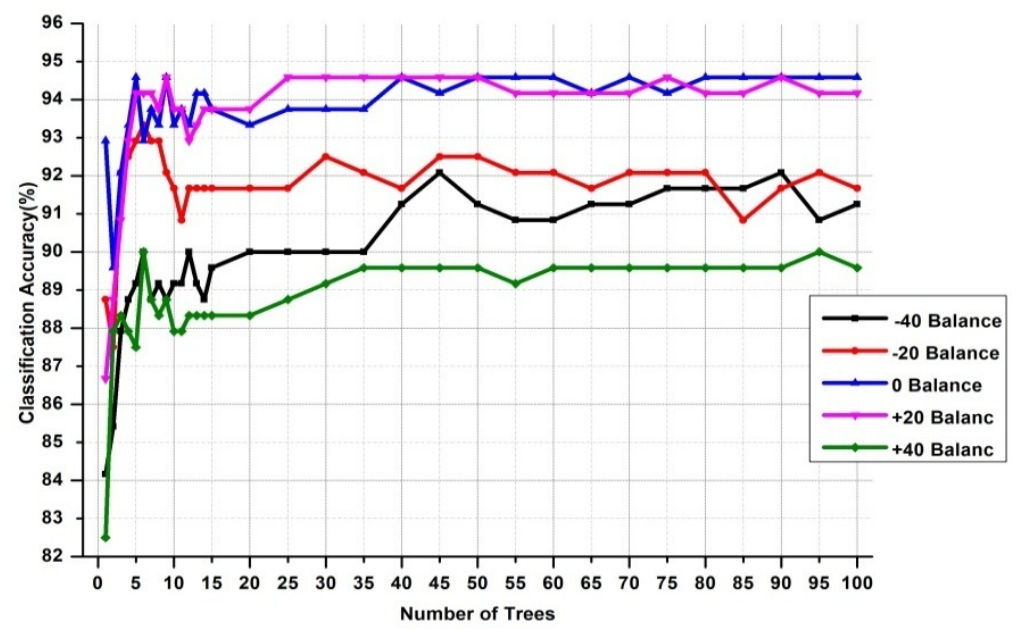

Figure 6: Number of Trees Varies with Classification Accuracy.

\section{CONCLUSIONS}

In the fast growing automobile industry tyre condition monitoring system has its own importance because safety is an important factor. This work showed an algorithm based comparison of different vibration signals obtained from nitrogen filled tyres under five different balancing conditions. Total five data models were created using random forest classifier and compared using data modeling technique. These created models were validated through 10 -fold cross validation and obtained good accuracy.From the balanced condition at $40 \mathrm{~g}$, other balance conditions were created by reducing or increasing mass. This methodology may be adopted for tyre condition monitoring because the error rate was considerably less. In future, one can modify the methodology by incrementing the mass by $5 \mathrm{~g}$ toimprove the accuracy. Also monitor the small changes in classification accuracy.

\section{REFERENCES}

1. Anoop P S. V Sugumaran and Hemanth Mithun Praveen (2016), “Tyre Pressure Monitoring System Using Machine Learning Approaches - A Review,” International Journal of Control Theory and Applications, vol. 9, no. 51, pp. 371-382. 
2. B. Premarsha (2016), “Survey on Tire Pressure Monitoring System," International Journal of Engineering and Technical Research (IJETR), vol. 0869, no. 2, pp. 120-121.

3. D. J. Schuring and S. Futamura (1990), “Rolling Loss of Pneumatic Highway Tires in the Eighties,” Rubber Chemistry and Technology, vol. 63, no. 3, pp. 315-367, doi: 10.5254/1.3538261.

4. R. H. Howard, H. R., NcGinnis, T. A., Daugherty (1993), “Remote Tire Pressure Sensing Technique,”.

5. I. A. Craighead (1997), "Sensing tyre pressure, damper condition and wheel balance from vibration measurements," Proceedings of the Institution of Mechanical Engineers, Part D: Journal of Automobile Engineering, vol. 211, no. 4, pp. 257-265, doi: 10.1243/0954407971526416.

6. N. N. Hasan, A. Arif, and U. Pervez (2011), “Tire pressure monitoring system with wireless communication,” 2011 24th Canadian Conference on Electrical and Computer Engineering(CCECE), pp. 99-101.

7. Z. Marton, D. Fodor, K. Enisz, and K. Nagy (2015), “Frequency analysis based Tire Pressure Monitoring,” 2014 IEEE International Electric Vehicle Conference, IEVC 2014, pp. 0-4, doi: 10.1109/IEVC.2014.7056187.

8. B. Wu, Y. Fang, and L. Deng(2019), "Summary of Energy Collection Application in Vehicle Tire Pressure Monitoring System," in Proceedings of the 2019 4th International Conference on Automation, Control and Robotics Engineering, doi: 10.1145/3351917.3351918.

9. J. Ryan and D. Bevly (2012), Tire radius determination and pressure loss detection using GPS and vehicle stability control sensors, vol. 8, no. PART 1. IFAC.

10. D. Garcia-Pozuelo, J. Yunta, O. Olatunbosun, X. Yang, and V. Diaz(2017), "A strain-based method to estimate slip angle and tire working conditions for intelligent tires using fuzzy logic,” Sensors (Switzerland), vol. 17, no. 4, doi: $10.3390 /$ s 17040874 .

11. O. Svensson, S. Thelin, S. Byttner, and Y. Fan(2017), "Indirect Tire Monitoring System - Machine Learning Approach," IOP Conference Series: Materials Science and Engineering, vol. 252, no. 1, doi: 10.1088/1757$899 X / 252 / 1 / 012018$.

12. P. S. Anoop, V. Sugumaran, and H. Mithun Praveen(2016), "Implementing K-Star Algorithm to Monitor Tyre Pressure using Extracted Statistical Features from Vertical Wheel Hub Vibrations, ” Indian Journal of Science and Technology, vol. 9, no. 47, pp. 1-7, doi: 10.17485/ijst/2015/v8i1/107926.

13. R. F. McLean, S. H. Alsop, and J. S. Fleming(2005), “Nyquist-overcoming the limitations," Journal of Sound and Vibration, vol. 280, no. 1-2, pp. 1-20, doi: 10.1016/j.jsv.2003.11.047.

14. P. S. Anoop and V. Sugumaran(2017). “Classifying machine learning features extracted from vibration signal with logistic model tree to monitor automobile tyre pressure,” SDHM Structural Durability and Health Monitoring, vol. 11, no. 2, doi: 10.3970/sdhm.2017.011.191.

15. S. Sasikala, S. Bharathidason, and C. J. Venkateswaran(2015). "Improving Classification Accuracy based on Random Forest Model through Weighted Sampling for Noisy Data with Linear Decision Boundary,” Indian Journal of Science and Technology, vol. 8, no. April, pp. 614-619, doi: 10.17485/ijst/2015/v8i. 
16. R. Satishkumar and V. Sugumaran(2016). “Vibration based Health Assessment of Bearings using Random Forest Classifier,” Indian Journal of Science and Technology, vol. 9, doi: 10.17485/ijst/2016/v9i10/85303.

17. Anoop P S. V Sugumaran and Hemanth Mithun Praveen(2018), "Analyzing Vertical Vibrations Of Automobile Wheel Hub To Monitor Tyre Pressure Using Statistical Features And Support Vector Machine Algorithm,” Pakistan Journal of Biotechnology, vol. 15, no. Special Issue ICRAME 17, pp. 10-13.

18. Anoop P.S. and V. Sugumaran (2018), "Tyre Pressure Monitoring System Using Statistical Analysis And Rotation Forest Algorithm,” Pakistan Journal of Biotechnology, vol. 15, no. Special Issue ICRAME 17, pp. 36-39. 